\title{
SEISMIC WAVES TRAVELING THROUGH A DIKE-LIKE STRUCTURE
}

\author{
Yoshinobu Motoya \\ Research Center for Earthquake Prediction, Faculty of Science, \\ Hokkaido University, Sapporo, Japan
}

(Received March 6, 1989; Revised July 1, 1989)

In this letter we report a characteristic wavelet observed at Hidaka (HIC) station, one of the seismographic stations operated by the Research Center for Earthquake Prediction, Hokkaido University. A main shock-aftershock sequence occurred near HIC on June 17, 1980 (Fig. 5). All the six events of the sequence observed at HIC showed a small but conspicuous wavelet before the large main phase (Fig. 1).

The characteristics of the wavelet are summarized as follows. On the basis of the principal component analysis of the particle motions of a seismic signal, MONTALBETTI and KANASEWICH (1970) defined the rectilinearity which will give an estimate of the degree of polarization along the major axis. Application of this method to the waveform data of the main shock reveals that both the wavelet and the main phase are longitudinal, $\mathbf{P}$ wave, as they are polarized linearly with rectilinearities of 0.91 and 0.61 , respectively. The duration time of the wavelet and its amplitude ratio to the main $\mathbf{P}$ phase are nearly identical among the events, ranging from 0.77 to $0.80 \mathrm{~s}$ and from 0.09 to 0.13 , respectively. Through the wavelet, amplitudes are rather constant and periods are surprisingly steady (Fig. 2). No pulsive phase is seen in the wavelet. The spectral structure of the wavelet is clearly different from that of the following main $\mathrm{P}$ phase. The wavelet is monochromatic (Fig. 3A). Another noticeable feature is that the wavelet is not observed at any station near HIC.

In order to explain the characteristics of the wavelet, we assume a $\mathrm{P}$ wave transmitting through a bar-like structure; the quantity of both amplitudes and periods of incident seismic waves might turn to the characteristic one which is dependent on the shape of the bar. We performed a model experiment to simulate the generation of the wavelet. The configuration for observing waveforms is exhibited in Fig. 4. The superficial layer in the model is made of a plastic plate whose thickness $H 1$ is $240 \mathrm{~mm}$. The lower layer is made of an aluminum plate whose thickness $H 2$ is $1,050 \mathrm{~mm}$. An aluminum tip protrudes from the boundary of the two layers into the plastic plate. We fixed the position of the tip, but changed the width of the tip $w$ from 6 to $17 \mathrm{~mm}$ and/or its height $h$ from 45 to $120 \mathrm{~mm}$. Both a receiver and a transmitter of the piezoelectric transducer with a resonance frequency of $5 \mathrm{MHz}$ 


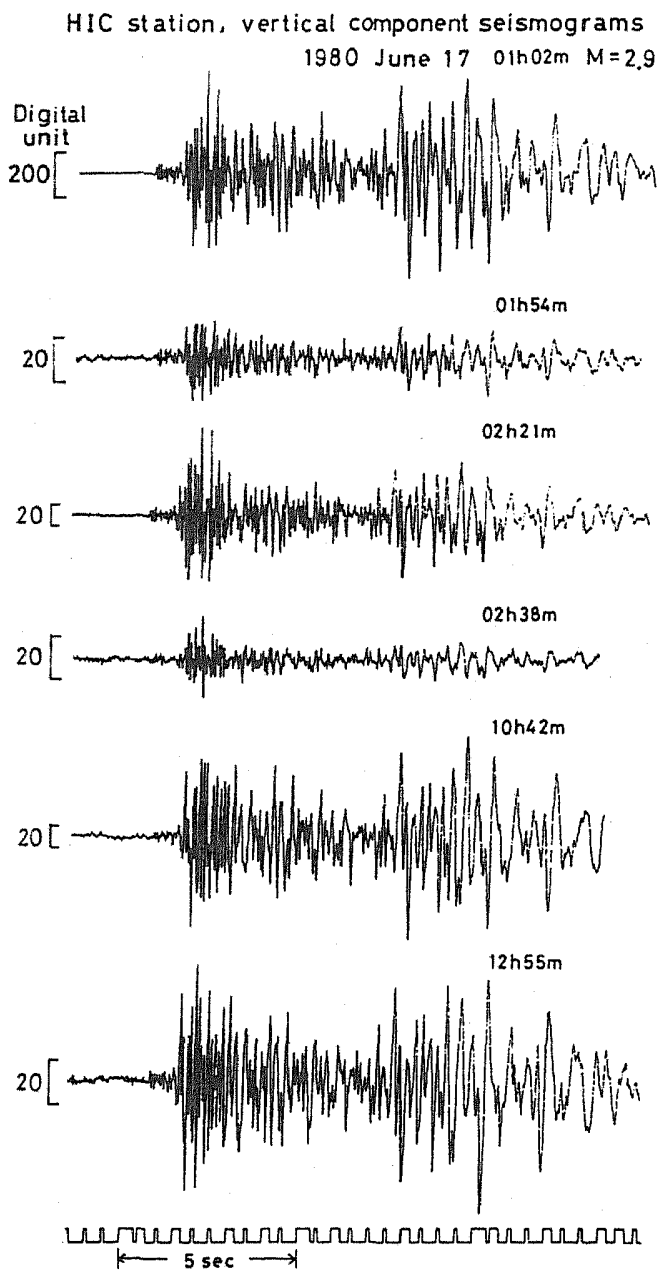

Fig. 1. Seismograms of microearthquakes composing a main shock-aftershock sequence. Hypocentral parameters of the main shock (top trace) are $43.137^{\circ} \mathrm{N}$, $142.581^{\circ} \mathrm{E}$, depth $25 \mathrm{~km}$, and $M 2.9$. Aftershocks (lower five traces) are not located because of their small magnitudes.

are attached to the upper and the lower edge of the model, respectively. We moved the position of the receiver and/or source (transmitter) along the edges of the model. Thus, we observed waveforms in various configurations of source-tip-receiver.

Similar wavelets as mentioned above are observed successfully in the case where the positions of the transmitter and the receiver are proper to the shape of the aluminum tip protruding into the plastic plate. A tip with the size $w=6 \mathrm{~mm}$ and $h=120 \mathrm{~mm}$ is the most effective for generating the wavelet in our experiments (Fig. 4A). Departure from this size produces an inferior wavelet. For example, a tip with 
HIC station, 3 component seismograms

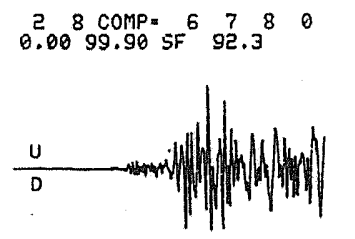

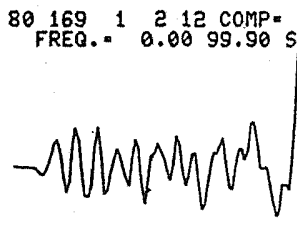

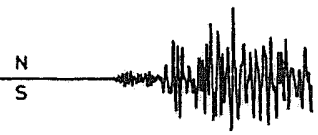

- NAPNAMNAI
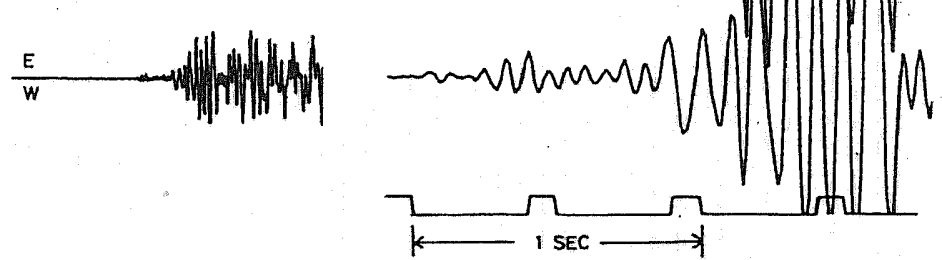

Fig. 2. Details of the initial part of the seismogram of the main shock.

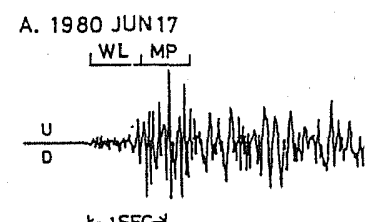

B. 1977 SEP 03

C. 1979 APR 22

- ISEC $\rightarrow 1$
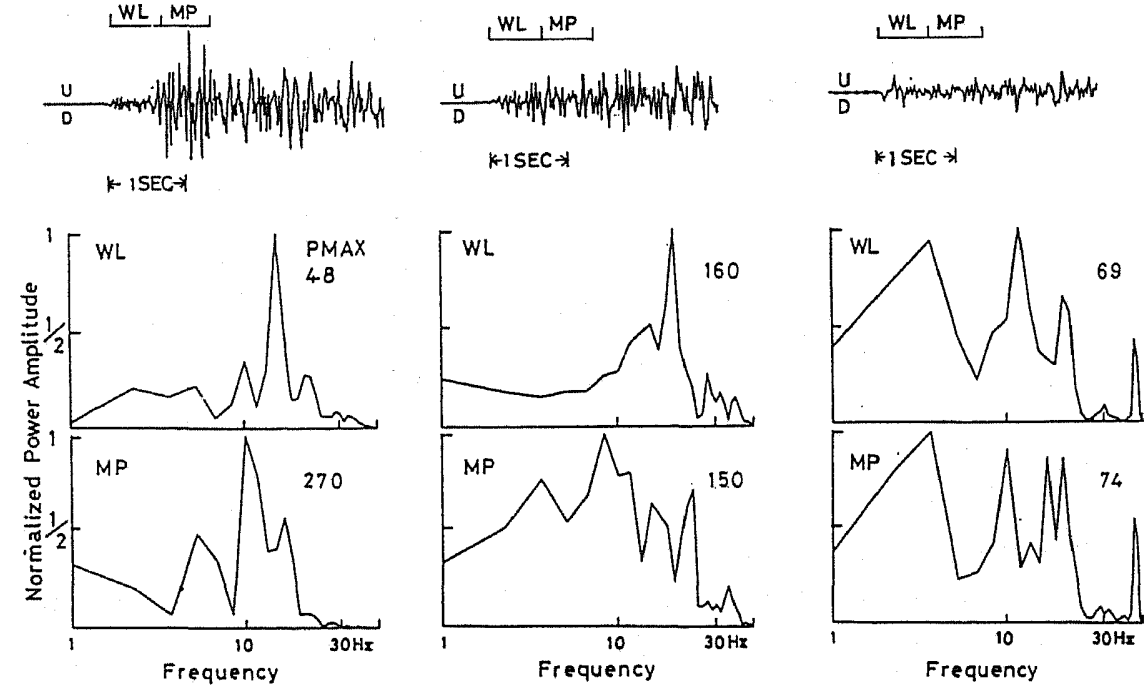

Fig. 3. Spectral analysis of the initial part of $P$ waves. Locations of the events (A, B, C) are shown in Fig. 5. 

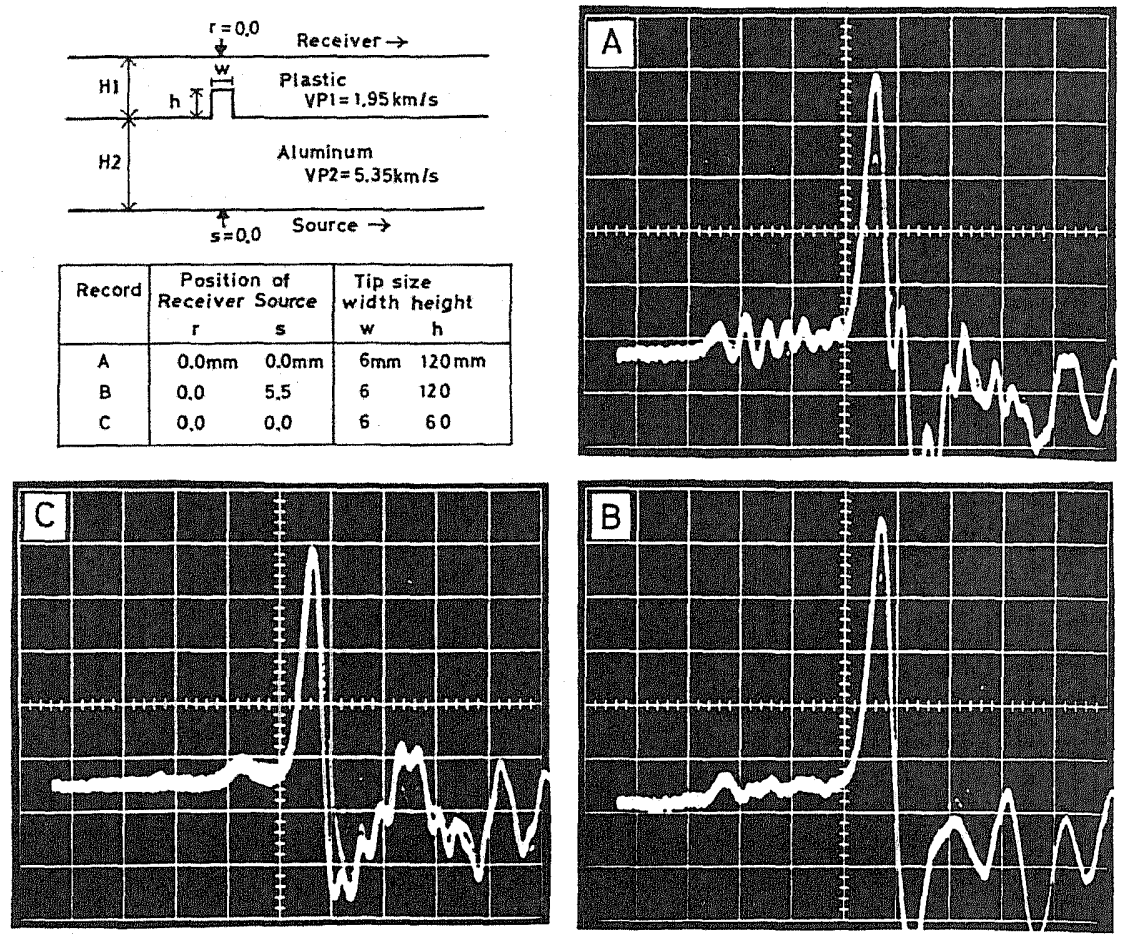

Fig. 4. Configuration of the model experiment and examples of waveforms observed. Time scale and sensitivity in each display are $5 \mu \mathrm{s} / \mathrm{div}$ and $10 \mathrm{mV} / \mathrm{div}$, respectively.

the same width but another height, $h=60 \mathrm{~mm}$, hardly generates the wavelet (Fig. $4 \mathrm{C}$ ). The wavelet becomes also poor with increasing angle $\alpha$ between the vertical line containing the tip and the line connecting the tip and the transmitter (Fig. 4B). The wavelet is no longer observed beyond around $\alpha=10^{\circ}$. Because the primary purpose of our experiments is to check the generation of the wavelet qualitatively, it is not so serious that the velocity contrast of the tip to the surrounding medium seems to be unrealistically large, compared with a probable one under the field. Moreover, as stated later, extremely high velocity contrasts may exist under the region concerned.

In the natural field, a dike-like structure may produce such a wavelet. It is easily imagined, however, that there seldom exists a suitable configuration of seismic source/dike-like structure/seismographic station for observing the wavelet. Through the seismic observation over ten years, there have been only two other events which might satisfy the configuration (B and C in Fig. 5). While the wavelet is not seen so clearly on the seismogram, the event $B$ has the similar spectral structure to that of the event $A$ which showed the typical wavelet as mentioned above (Fig. 3B). The 


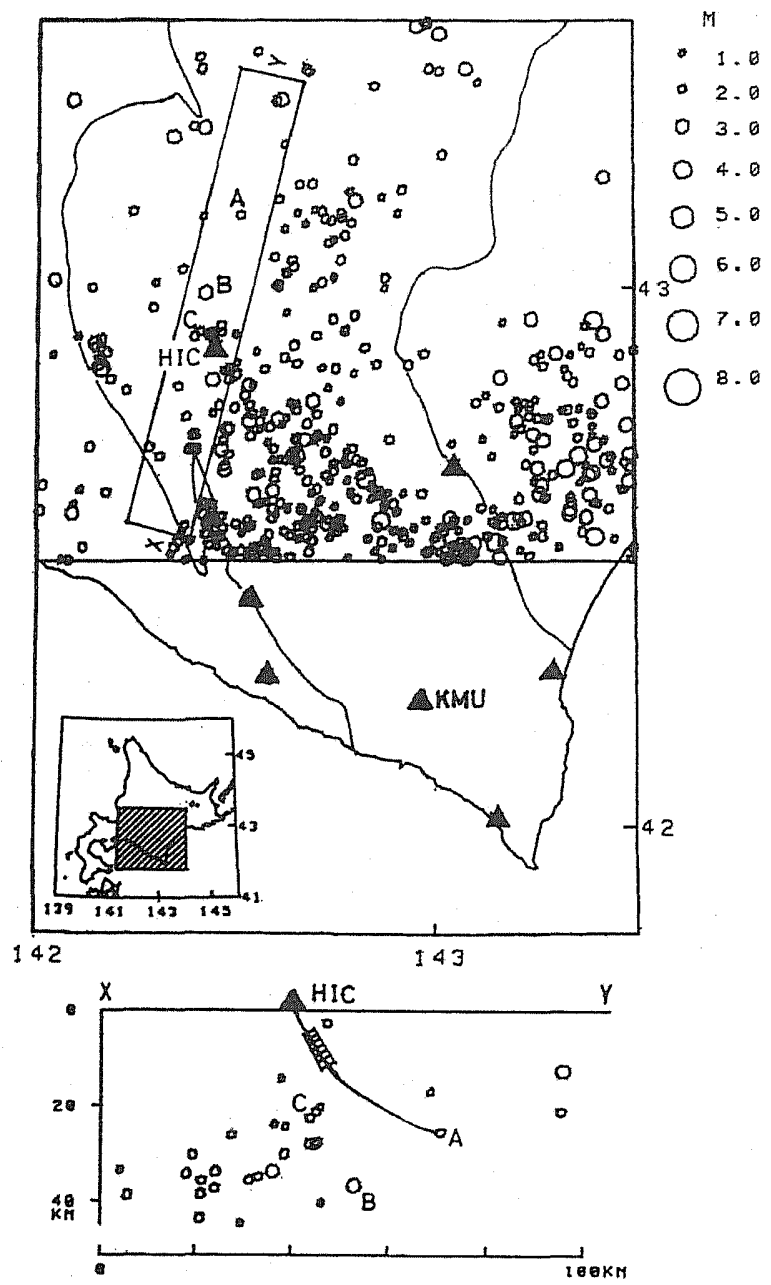

Fig. 5. Seismographic stations (triangles) of the Research Center for Earthquake Prediction of Hokkaido University and RCEP hypocenters of earthquakes (circles) shallower than $50 \mathrm{~km}$ through July 1976 to June 1988 . The event A is the main shock on June 17, 1980. Spectra of the events A, B, and C are shown in Fig. 3. The central region bounded by two curves is the Hidaka orogenic belt. A seismic ray and a possible dike-like structure (hatched) are depicted schematically in the $\mathrm{X}-\mathrm{Y}$ cross section.

event $\mathrm{C}$ shows no more evidence of the wavelet (Fig. 3C). The two events should indicate a constraint to the position of the dike-like substance. Anyway, it is interesting to have observed such a wavelet that could reveal the microscopic structure buried.

It has been pointed out that remarkable wavelets prior to the large main $\mathbf{P}$ 
phases are frequently observed at Kamikineusu (KMU) station from earthquakes occurring east off Hokkaido (MоTоYA, 1972). The characteristics of the wavelet are similar to those of the preceding wavelet observed at HIC. Both HIC and KMU are located on the Hidaka orogenic belt which has undergone a long and extremely complex geological development (Fig. 5). The Hidaka region containing the orogenic belt is characterized by strong velocity anomalies (TAKANAMI, 1982; MIYAMACHI and MorIYA, 1984). Possibly there are some dike-like structures under this area, though the wavelets observed are not related directly to bodies confirmed geologically. YAMAGUCHI (1987) showed that the precursory wavelet to P phase observed at KMU can be explained by a high velocity body of $25 \mathrm{~km}$ width dipping toward the east with $50^{\circ}$ down to a depth of $45 \mathrm{~km}$ beneath the Hidaka mountains. In his estimate, an extremely high velocity contrast is required; the body must have a velocity $40 \%$ higher than that of the surroundings. Though such structure is rather large scale, beyond the terminology of dike, we think that it is interesting that it works effectively in generating the wavelet, as does our experiment.

I am indebted to Dr. I. Maeda of the Research Center for Earthquake Prediction of Hokkaido University, who contributed his skill to the model experiment.

\section{REFERENCES}

MIYAMACHI, H. and T. MoRIYA, Velocity structure beneath the Hidaka mountains in Hokkaido, Japan, J. Phys. Earth, 32, 13-42, 1984.

MontalbetrT, J. F. and R. KaNASEWICH, Enhancement of teleseismic body phases with a polarization filter, Geophys. J. R. astr. Soc., 21, 119-129, 1970.

MoTOYA, Y., Earthquake observation at the Urakawa Seismological Observatory (III), Geophys. Bull. Hokkaido Univ., 27, 55-65, 1972 (in Japanese).

TAKANAMI, T., Three-dimensional seismic structure of the crust and upper mantle beneath the orogenic belts in southern Hokkaido, Japan, J. Phys. Earth, 30, 87-104, 1982.

YAMAGUCHI, K., Analysis of precursors to P phases observed at station KMU, Thesis for Master's Degree presented to Hokkaido Univ., 1-65, 1987 (in Japanese). 